\title{
Passing On The Baton: Professional Nurses As Role Models in Professional Socialisation of Leaner Nurses in Limpopo Province.
}

\section{Julia Mafumo}

University of Venda

Lizzbeth Netshikweta

University of Venda

Maria Maputle ( $\sim$ Sonto.Maputle@univen.ac.za)

University of Venda

\section{Research Article}

Keywords: Professional nurse, learner nurse, professional socialisation, role model

Posted Date: January 18th, 2021

DOI: https://doi.org/10.21203/rs.3.rs-132994/v1

License: (c) (i) This work is licensed under a Creative Commons Attribution 4.0 International License.

Read Full License 


\title{
PASSING ON THE BATON: PROFESSIONAL NURSES AS ROLE MODELS IN PROFESSIONAL SOCIALISATION OF LEARNER NURSES IN LIMPOPO PROVINCE
}

\section{Corresponding author: Mrs. Mafumo JL, julia.mafumo@univen.ac.za}

University of Venda, School of Health Science, Department of Advanced Nursing, Private Bag x5050, Thohoyandou, 0950, Limpopo Province, South Africa.

University of Venda, School of Health Science, Department of Advanced Nursing, Private Bag x5050, Thohoyandou, 0950, Limpopo Province, South Africa.

Professor Netshikweta ML, Lizzy.Netshikweta@univen.ac.za

University of Venda, School of Health Science, Department of Advanced Nursing, Private Bag x5050, Thohoyandou, 0950, Limpopo Province, South Africa.

Professor Maputle MS, Sonto.Maputle@univen.ac.za

\begin{abstract}
Background: Professional nurses play a significant role in the professional socialisation of learners as learners look up to them as seniors. Learners come into the profession with the values and norms from the different societies where they grew up. These learners do not possess the ethics and skills in the nursing profession and rely on professional nurses to pass these qualities. The objective of the study was to explore the perception of professional nurses regarding their role as role models in the profession.
\end{abstract}

Methods: A qualitative, explorative design was used to collect data from professional nurses. No probability purposive sampling was used to select professional nurses working at sampled hospitals where learners are placed for clinical practice. The selection criteria were an experience of three years and above in professional socialisation of learners. Data was collected through a semi structured interview. An interview guide was used to ask the appropriate questions related to the role modelling of professional nurses in the profession. Data was collected until saturation was reached. Tesch's open coding system was used to analyse data 
Results: The findings revealed that professional nurses acknowledged their responsibilities role modelling of the profession in professional socialisation of learners. Three main themes that emerged from the study were professional nurses as mentors, professional nurses as teachers and professional nurses as competent practitioners. Professional nurses were aware of their role in transferring the ethical skills and knowledge to learners during clinical placement. However professional nurses also acknowledged that there were incidences where professional nurses behave in a manner that does not promote exemplary role modelling.

Conclusion: The professional nurses should uphold the moral ethics of the profession always to teach learners the correct and acceptable behaviour and conduct in the profession. Children learn from adults therefore the learners copy the conducts of the adults in the profession. Through teaching in the clinical areas, professional nurses transfer the skills that they have. Mostly teaching in the clinical areas is informal and observed. Therefore, professional nurses should use teachable moments to transfer skills. Lastly the professional nurse is expected to be a competent practitioner. Learners learn these skills when professional nurses are executing them. The competent practitioner is also confident in practice.

Key words: Professional nurse, learner nurse, professional socialisation, role model

\section{Background}

Professional socialization is described as a process by which the neophytes of the nursing profession acquire the specialized knowledge; skills; attitudes, values, norms; and interests needed to perform their roles acceptably (Moradi, Mollazadeh, Jamshidi, Tayefeh, Zaker, \& Karbasi 2017). Professionally, it is necessary to involve the learner nurses in the professional practice, since this process also includes the integration of the cognitive and affective domains of professional performance that governs individual behaviour.

Professional nurses serve as role models to learner nurses in the clinical areas. When learner nurses are in the clinical learning areas, they are under the supervision and guidance of professional nurses. Professional nurses as the custodians of teaching and learning in the clinical areas, are responsible for passing on the values and 
principles of the profession through professional socialisation. The foundation of the study was on Bandura's Social Learning theory which states that young people emulate the behaviour of the adult person in their environment as they consider them as their role models. In this instance the professional nurses are adults in the professional environment and learners will imitate their behaviour as they consider them as role models.

Nursing is a science and art which consist of conceptual and practical knowledge. Student nurses integrate theory and practice in clinical learning areas under the supervision of professional nurses. Nursing education also involves learning the expected moral and ethical behaviours of the profession. Professional nurses are expected to pass the professional values like caring, compassion, empathy, sympathy and honesty to learners. These learner nurses in the clinical learning areas can only learn that if the professional nurses act as exemplary role models all the time. This is the reasons why the professionals who qualify as professional nurses are required to be prepared and empowered through professional socialisation to equip them with what the profession and the society demands of them. Professional socialisation is considered as anticipatory socialisation, which refers to the formation and internalisation of the characteristics that are typical of a profession (Dinmohammadi, Peyrovi \& Mehrdad, 2017). It has been indicated by De Swardt, Van Rensburg and Oosthuizen (2014) as the process of involving learners of a professional group getting immersed in the professional culture. It is a process that begins with getting acquainted with the professional roles and gaining a professional identity.

The professional values associated with nursing, serve to guide the nurse's behaviour so that it complies with the profession's preferred standards. The values can be passed to learner nurses through role modelling. One of the most consequential and enduring aspects of training to become a professional nurse is that the process shapes one's professional identity (Dinmohammadi et al., 2017). In the Nursing Education Summit held in Sandton in South Africa, it was alluded that the attitudes of nurses have changed over the years ( $\mathrm{DOH} 2016)$. The minister of health during that time even included the nurses' attitudes as his ministerial priorities in the country.

The purpose of educating student nurses is to ensure that upon completion of the programme, the qualifiers should be able to provide quality nursing care to clients, 
family and patients per the standard set by the profession. Positive role models in the clinical learning areas provide the learner with the opportunity to observe good practice and can imitate the practice (Brown, Stevens \& Kermonde 2011; Tang and Chang 2019). A study by Setati and Nkosi (2017) in Limpopo Province, South Africa, found that learner nurses copy what they observe from the professional nurses whom they value as their mentors which further enhances professional socialisation.

\section{Methods}

\section{The design}

The study was a qualitative explorative design whereby the researcher wanted to explore the perception of professional nurses regarding their role in the professional socialisation of learner nurses. Professional nurses as people given the responsibility to supervise learners in the clinical areas (SANC), they were responsible for professional socialisation.

\section{Sampling}

Four hospitals in two districts of the Province where learner nurses training for R425 programme were allocated for clinical learning were purposively selected as these were the areas of professional socialisation. The hospitals were selected according to the different level of care which they provide in order to obtain the perception of professional nurses in all the levels of care in the Province. A District, Regional and Tertiary hospitals were selected. The population was professional nurses who were purposively sampled. The inclusion criteria for professional nurses was that they should have been in professional socialisation of learners for a period of not less than three years.

\section{Data collection}

Data was collected through a one on one semi-structured interview using an interview guide. The interview guide was used during data collection (Table 1). The interview guide was developed based on the literature review and the experience of the researcher as a clinical nurse educator. The interviews were held at the venues provided by the institutions. The participants were interviewed during their convenient times in order to avoid disturbances of services in the hospital. Each interview lasted 
for 45-55 minutes. The researcher also probed participants to give clarity on some points given. Field notes were taken where important information that had impact and were of significance were recorded. A tape recorder was used to capture the narrative data so that the researcher could listen and compare them to the field notes after data collection. Data was collected until saturation was reached.

Table 1 The interview guide

The open-ended questions

1. What is your perception regarding your role in professional socialisation of learners?

2. How could your behaviour influence the professional socialisation of learner nurses?

3. What do you think you could assist the learners with during professional socialisation?

\section{Data analysis}

Tesch's open coding method was used to analyse data. During analysis, the concepts that belonged together were grouped together to form themes and subthemes. This method is a useful when a researcher is working within a participatory research paradigm with participants as collaborators. During data analysis, the researcher read through all the transcripts carefully, to gain a sense of the whole several times, to acquaint the researcher with data collected and jotting down some ideas which came to mind, similar topics were clustered together. After data was coded, it was reduced and examined closely for similarities and differences. Similar data were grouped into main themes, themes and sub themes.

\section{Ethical considerations}

After obtaining ethical clearance from the University of Venda Research Ethics Committee (SHS/19/PDC/04/1103), letters for requesting to collect data were sent to the Department of Health in the Province, District and sampled institutions where 
permissions to conduct the study was granted. Participants were explained about the purpose of the study, the right to decline participation, the right to privacy, the right to free from harm. A consent was obtained from the participants before the study was conducted.

\section{Rigour}

Trustworthiness of a research study is important in evaluating its worth and credibility (Henry 2015). Trustworthiness refers to the degree of confidence qualitative researchers have in their data assessed using the criteria of credibility, transferability, dependability and confirmability (Polit \& Beck 2017). For prolonged engagement, the researcher collected data over a period of eight months allowing more time spent with the participants so that in-depth understanding of the phenomenon of professional socialisation of learner nurses was obtained. Member checking was done throughout by deliberate probing and asking for clarity during the interviews and confirming the findings with the participants after data collection. Confirmability was ensured by storing the voice records, field notes and transcripts of the collected data in case there is an audit that needs to be done.

\section{Findings}

The findings of this study were presented in three themes. The three themes that emerged were:

1. Professional nurse as a mentor

2. Professional nurse as a teacher

3. Professional nurse as a competent practitioner

\section{Theme 1: Professional nurses as mentors}

Findings in the study revealed that professional nurses consider themselves as mentors to learners. A mentor is defined as a relationship consisting of assessing, supervising, preceptoring and coaching of learners by professional nurses in the clinical learning areas (Foolchand \& Maritz 2020). As mentors, professional nurses are expected to guide and couch learners. 


\section{Sub-theme: 1.1 The appearance of the professional nurse}

The findings revealed that professional nurses viewed they appearance and the way they dress as influences on how learner nurses view the profession. The appearance of a professional nurse indicates the image of the profession. Regulation 1201 of the Nursing Act, (33 of 2005) states how the uniform of the nurse should be worn. The uniform is not only the attire but the inclusion of distinguishing devices. If the professional nurses put on the uniform as prescribed the institution, learner nurses will be able to copy and feel that them too have the responsibility to put on the prescribed uniform. The professional image of nursing, creates a context in which the public views nurses and the nursing profession. The professional image of a nurse is emotionally connection with a patient and the nurse and the care that the patient receives (Hatfield, Pearce, Del Guidice, Cassidy, Samoyan, \& Polomano, 2013). One participant said:

"My perception of my role as a professional nurse in professional socialisation is that I must be a role model. The professional nurse must always be in a complete full uniform with distinguishing devices. The hair style must also be acceptable not like where a person can have pink or purple coloured hair. If as the professional nurses I am like that, the students will see how I dress and want to be like me.

Shaw and Timmons (2010) share the sentiment that nurses uniform hold personal significance especially to those who wear it and it also uphold the value of nursing heritage and tradition. Furthermore, they argued that the uniform also acts as a powerful symbol that represent the professional identity and image. Therefore, the professional nurses need to be in full uniform to uphold the image of the profession which is part of professional socialisation. Wills, Wilson, Woodcock, \& Gillum (2018) shared the sentiments through their study which indicated that a person with a good professional image is portrayed as more professional and this conduct influence professional socialisation of learners.

\section{Sub-theme 1.2: The conduct of the professional nurse}

In this sub theme, professional nurses indicated their role in their behaviour and conduct that influence the professional socialisation of learners. The professional 
nurse as the role model needs to behave in a manner that will uphold the moral and ethical codes of the profession. Again, learner nurses see professional nurses as role models and whatever they do the student might want to imitate. Cunze (2017) indicated that exposure of learners to positive behaviours by professional nurses in the clinical learning environment, provide the learner with opportunities to develop their own professional behaviours by observation and imitation. The author further stated that the characteristics and behaviours that are requested from professional nurses for them to act as role models are positive attitudes and behaviour, high self-esteem, honesty, trustworthiness, reliability, self-respect, integrity, fairness and energy. Nursing has its values and characteristics which all who are in the profession should adhere to (Niederriter, Eyth \& Thoman 2017). In support of the above, the participant said:

"My role in professional socialisation is to be a role model. I must behave in such a way that it is not bad for learners to copy wrong things. I must speak to patients and staff politely in a respectable manner and not shout at people. Also as a professional nurse I must always tell the truth and not lie. I must not steal patient food because if I do that, learners will be observing and they must do the same tomorrow."

As indicate earlier, negative role modelling is bad for professional socialisation of learner nurses as students look up to professional nurses as their role models. A study by De Swardt, Van Rensburg and Oosthuizen (2017) support the negative role modelling where students were exposed to situations where professional nurses were behaving inappropriately. When learner nurses come to the nursing profession they are like blank pages wherein the professional nurses should put in the profession through role modelling. Negative role modelling can at times lead to student emulating such practice leading to poor outcomes of professional socialisation (Jack, Hamshire \& Chambers 2017). Contrary to that, even if the learner observes the negative behaviour from professional nurses, ultimately it is the learner who should make the decision to repeat or not the negative behaviour. 


\section{Theme 2: Professional nurse as a teacher}

\section{Sub-theme 2.1: Providing teaching}

The findings of the study also revealed that professional nurses were willing to teach learners. Professional nurses felt that they need to teach learners and evaluate their performance. They accepted teaching of learners in the clinical areas as their responsibility and indicated the significance of teaching to learners. The following transcripts support the theme:

"My role in professional socialisation of learners is to teach them when they are in the clinical learning areas. In our ward, we have a teaching programme where we offer teaching three times a week on the common conditions that are in the ward. We even delegate learners to teach. Also during performance of procedures, I usually want the student to be nearby so that I teach them what I am doing and give them the opportunity to ask questions".

The professional nurse has the responsibility to teach students. Meyer, Naudé, Shangase and Van Niekerk (2011) indicated that the responsibilities of the professional nurse in the clinical area include provision and supervision of patient care, unit administration, teaching and research. When learner nurses are in the clinical learning areas, they need to be assisted to integrate the theory acquired at the NEIs with the activities in the clinical learning environment. Professional nurses were aware of the obligation to do so. Professional nurses indicated their obligation to provide feedback to learners at the end of each clinical placement. The findings are supported by a study in Australia by Anderson, Moxham and Broadbent (2018) revealed that the professional nurses have insight about their teaching function to learner nurses. The authors further indicated that the professional nurses believed that teaching students is the right thing to do and they have the responsibility to ensure that it happens. 


\subsection{Providing support to learners}

Professional nurses indicated their willingness to support learners during clinical placement. Clinical learning environment could be stressful to learners especially during the first placements. A comparative study by Jarvinen et al. (2016), indicated that learner nurses often have high level of stress compared to students from other disciplines such as science and law so learning under stress can be very disturbing and might make it difficult to learn. If the stress in the clinical learning area is not effectively handled, it might affect professional identity and socialisation wherein learners will fail to correctly fit in the profession (Graham, Lindo, Bryan \& Weaver 2016). In support of that, the professional nurses said:

"During the first year of clinical placement, learners are often shy and scared and not free. They also don't know what to do or what to ask. I ask the students about what is that they want to learn and when they tell me I make an appointment to teach them. I also ask about how they are coping, whether they have any challenges and even ask about their wellbeing".

Sometimes these learner nurses struggle to find appropriate ways where they can fit especially in the clinical learning areas as they need to maintain the balance between the prevailing values from the university and college (Ewertsson, Bagga-Gupta \& Blomberg 2017). Hence the professional nurses should come in to support the learners to find their feet and help them to be properly socialized into the profession and respect the ethics and morals of the profession. The journey to professional socialisation is not a smooth one where one must suddenly adopt and adapts to a certain way of behaviour and conduct making. The people who can help hold the hand of learner nurses in this journey are professional nurses as they are the custodians of teaching and learning in the clinical learning areas. 


\section{Theme 3: Professional nurse as a practitioner}

\section{Sub-theme 3.1: Competency}

The findings revealed that professional nurses are aware of their responsibilities to teach learners to do the right thing. They indicated the significance of being competent in problem solving, communication and provision of care. The findings were supported by Lamont et al. (2015) who indicate that competency is one of many factors that influence positive clinical placement which is important in professional socialisation of learners. A study by Muthathi, Thurling, \& Armstrong (2017) affirms the findings by indicating that professional nurses have the responsibility and accountability to ensure that patient receives quality care and that they have a moral duty to teach, mentor and supervise learners during clinical placement to ensure that learners can provide quality patient care and ensure safety. The issue of competency was stressed by many professional nurses, one of them said:

"The role that I play as the professional nurse in the professional socialisation of learners is that I must be competent in whatever I do in the clinical learning environment. In the ward, there are many activities that are done that I am involved with in daily basis. I can't be with student and do wrong things in front of the students".

The scope of practice R786 of the Nursing Act (33 of 2005), indicate that the professional nurse is expected to be competent in provision of care to patient. Competency starts during training though professional socialisation and continues throughout the practicing career of an individual. Competency is associated with patient safety so professional nurses need to be competent so that learner nurses under their supervision and professional socialisation can be competent.

\section{Sub-theme 3.2: Patient advocacy}

Findings indicated that the professional nurses have insight about their role in the advocating of patients' rights. They indicated that as role models they need to teach learners on how to protect the rights and dignity of the patients. According to the 
Constitution of the country, every human being should be treated with respect and dignity irrespective of the social standing. Patients too, have the rights. They further indicated that they need to advocate for the patient so that these patients receive the care that they desperately need. One participant said:

'My role in the professional socialisation of the learner nurse is to teach the learners how to advocate for the patients. Patients are often ignored and their care is compromised. In other instances, other members of the health team fail to properly communicate with the patient. In such cases I become involved to ensure that the rights of the patients are upheld. Also, I teach the learners that they should not keep quite whenever they see that something wrong is done to the patient".

The findings were supported by a study conducted in Ghana by Nsiah, Siakwa and Ninnoni (2019) who indicated that the responsibilities of the professional nurse are to protect the patient from harm, to be the voice of the patient, to support patient and to have a good interpersonal relationship with patients. Teaching learners the patient advocacy role is significant for professional socialisation of learners as these aspects should be acquired before the learner qualifies.

\section{Discussions}

Thematic analysis revealed that learner nurses viewed professional as their role models who influences their learning. As role models, professional nurses create an image for the student to aspire. Role modelling process does not only take place consciously; it can take place unconsciously and involuntary through acculturation and assimilation during the interaction. The way the professional nurse communicates with patients and colleagues influences how the learner will further engage in the profession. Professional nurses and clinicians are viewed as strong role models by learners.

As role models, professional nurses need to demonstrate therapeutic communication, critical thinking, compassion, enthusiasm and positive attitudes all the time in the clinical areas. This is supported by Gibbs and Kulig (2017) indicating that learners 
describe that the clinical instructors who in this case is the professional nurse, was an important factor in shaping their ability to think critically. De Swardt, Van Rensburg \& Oosthuizen (2017) in their studies on supporting students in professional socialisation concluded that students consider nurses in the clinical field are as the most influential role models in shaping their clinical practice, consequently their socialisation process. The studies further revealed that professional nurses in the clinical area who act as role models demonstrated good communication skills, positive attitudes, caring and excitement.

The presence of exemplary role models in nursing practice is very important as this kind of behaviour and attitude in the profession will empower the learners to have appropriate skills, knowledge, values and belief of the profession. Learners are inspired by professional nurses who have a positive attitude to challenging situations, who can multitask with diligence, who effectively communicate with patient, members of the health team and manage challenging clinical situations professionally. They consider such professional nurses to be role models and want to emulate such behaviour and conduct. The sentiment was also shared by Tang and Chang (2019) who indicated in their study that the clinical teachers, in this instance the professional nurses, implicitly acted as role models for the learners, enabling them to recognise the professional roles of nurses and shape their professional attitudes through a socialisation process.

In another study Mendes, da Cruz and Angelo (2015) students perceived that their instructors possessed both positive attitudes and a caring demeanour. The appearance of the professional nurse influences the image of the profession. Even how the professional nurses dress up in their uniform can influence the way the learner turns out to dress in the near future. The professional nurse's role in influencing the professional socialisation of the learner does not only help the student to succeed in their training but also in their personal and professional journey to become a competent and skilful practitioner one who is caring and compassionate, who cares for people in a humanising way and one who has the resilience to challenge those who are not demonstrating humanised care (White, Stainer, Cooper \& Waight 2018). 
In a situation where professional nurses act in a manner that does not uphold the moral and ethical principles of the profession, they are unintentionally sending the wrong message to the learners that it is "acceptable" to act as such. This is supported by Paliadelis and Wood (2016) in their study where in learners indicated that negative role models could have a positive influence on their practice and they demonstrated how reflections on negative events allowed them to re-imagine them more positively and vow not to act in the unacceptable manner.

The society expect nurses to be competent as competency leads to an improved quality of patient care and patient satisfaction (Karami, et al., 2017). Competent professional nurses will be able to transfer the skills to the learners through professional socialisation.

\section{Limitations of the study}

Even though the researcher made efforts to ensure trustworthiness of the study, qualitative studies often have challenges as they indicate the perception of one group of participants which. The study was conducted in rural areas and the limitation could be that if the study was in urban in areas, it might have yielded different results. The study concentrated on learner nurses in undergraduate studies, post graduate professional socialisation might yield different results too.

\section{Conclusion}

The professional nurses are aware of their roles as role models $s$ in the professional socialisation of learners. As role models to learners, should always act as an exemplary role model. Learners consider professional nurses as role models and will always aspire to be like them. Professional nurses also indicated the importance of providing support to learners so that the learners are free to learn and adapt in the clinical learning areas. The significance of creating an environment conducive to learning and communication was emphasised. The issue of professional nurses as competent practitioner was discussed wherein the professional nurse who is competent will be able to teach learners how to do things correctly and protect the patient from harm. Professional nurses also indicated that in their role modelling 
duties, they needed to protect the right of the patient from harm and abuse so that learners know how to protect the patients.

\section{Declarations}

\section{Acknowledgement}

The authors wish to thank the University of Venda and the University staff development Programme (USDP) for their support during the research and all the professional nurses who participated in the study.

\section{Funding statement}

The study was funded by the University of Venda and the University staff development programme (USDP), University of Venda and University of Free State.

\section{Availability of data and material}

Transcripts and audio recordings used to analyse data in the current study are available from the corresponding authors on request.

\section{Author's contributions}

Mafumo JL was the main researcher during in the Doctor of Nursing studies. Netshikweta ML was the main supervisor who assisted in guiding the process. Maputle MS was the co-promoter who guided the data analysis process and proof reading.

\section{Conflict of interest}

The authors declare that they have no competing interests.

\section{Consent for publication}

$\mathrm{N} / \mathrm{A}$

\section{Ethics approval and consent to participate}

This study received ethical approval (File No: SHS/19/PDC/04/1103) issued on March, 25, 2019 from the University of Venda Research Ethics Committee, Limpopo Province, South Africa. Permission to conduct the study was granted by the Limpopo Province, the Vhembe District and the Management of the institutions where data was collected. 
All participants provided informed, signed, written consent. All participants were informed of their voluntary participation and that they have the right to refuse or withdraw their participation anytime during data collection. Confidentiality of participants' identities was maintained throughout the study. The protocol was performed in accordance with the relevant guidelines and regulations.

\section{Authors details}

Corresponding author: Mrs. Mafumo JL, julia.mafumo@univen.ac.za

University of Venda, School of Health Science, Department of Advanced Nursing, Private Bag x5050, Thohoyandou, 0950, Limpopo Province, South Africa.

\section{Professor Netshikweta ML, Lizzy.Netshikweta@univen.ac.za}

University of Venda, School of Health Science, Department of Advanced Nursing, Private Bag x5050, Thohoyandou, 0950, Limpopo Province, South Africa.

\section{Professor Maputle MS, Sonto.Maputle@univen.ac.za}

University of Venda, School of Health Science, Department of Advanced Nursing, Private Bag x5050, Thohoyandou, 0950, Limpopo Province, South Africa.

\section{References}

Anderson, C., Moxham, L. \& Broadbent, M. 2018. Is provision of professional development by RNs to nursing students a choice? Australian Journal of Advanced Nursing, 35 (4), 34-41.

Braun, V. and Clarke, V., 2006. Using thematic analysis in psychology. Qualitative research in psychology, 3(2), 77-101.

Brown, J., Stevens, J. and Kermode, S. 2011. Supporting student nurse professionalism: The role of the clinical teacher. Nurse Education Today, 32(5), 606610. 
Creswell, J.W. \& Creswell, J.D., 2017. Research design: Qualitative, quantitative, and mixed methods approaches. Sage publications.

Cunze, M. \& Van Rensburg, G., 2016, 'The professional nurse as role model in the clinical learning environment', STTI, 27th international nursing research conference, Sigma Theta Tau International Honour Society, Cape Town, South Africa.

D'Souza, M., Venkatesaperumal, R., Radhakrishnan, J. and Balachandran, S. 2013. Engagement in clinical learning environment among nursing students: role of nurse educators, Open J Nurs, 3, 25-32.

Dadgaran, I., Parvizy, S. and Peyrovi, H. 2013. Nursing students' views of sociocultural factors in clinical learning: A qualitative content analysis, Japan Journal of Nursing Science, 10, 1-9.

De Swardt, H.C.R., Van Rensburg, G.H. and Oosthuizen, M. 2017. Supporting students in professional socialisation: guidelines for professional nurses and educators. International Journal of Africa Nursing Sciences, 6, 1-7.

Dinmohammadi, M. R., Peyrovi, H., \& Mehrdad, N. 2017. Professional socialization of Iranian BSN Students: A grounded theory study. Journal of Caring Sciences, 6(4),359-369. Journal of Caring Sciences, 6(4),359-369.

Gemuhay, H.M., Kalolo, A., Mirisho, R., Chipwaza, B. \& Nyangena, E. 2019. Factors Affecting Performance in Clinical Practice among Preservice Diploma Nursing Students in Northern Tanzania. Nurs Res Pract.; 2019:3453085.

Gibbs, S.S. and Kulig, J.C., 2017. "We definitely are role models": Exploring how clinical instructors' influence nursing students' attitudes towards older adults. Nurse Education in Practice, 26, pp.74-81. 
Hatfield, L.A., Pearce, M., Del Guidice, M., Cassidy, C., Samoyan, J.\& Polomano, R. C. 2013. The Professional Appearance of Registered Nurses: An Integrative Review of Peer-Refereed Studies. The Journal of Nursing Administration, 43(2), 108-112.

Henry, P., 2015. Rigor in qualitative research: Promoting quality in social science research. Research Journal of Recent Sciences ISSN, 2277, 2502.

Jack, K., Hamshire, C. \& Chambers, A. 2017. The influence of role models in undergraduate nurse education. J Clin Nurs. 26:4707-4715.

Karami A, Farokhzadian J, Foroughameri G (2017) Nurses' professional competency and organizational commitment: Is it important for human resource management? PLoS ONE 12(11): 0187863.

Lamont, S., Brunero, S. \& Woods, K.P. 2015. Satisfaction with clinical placement-the perspectives of nursing students from multiple universities. Collegian.;22:125-33.

Laske, R.A., 2019. Mentoring Nurses New to Day Camp Nursing Practice. Pediatric Nursing, 45(2).

Madhavanpraphakaran, G. K., Shukri, R. K., \& Balachandran, S. 2014. Preceptors' perceptions of clinical nursing education. The Journal of Continuing Education in Nursing, 45(1), 28-34.

Mendes, M. A., da Cruz, D. A. L. M., Angelo, M. 2015. Clinical role of the nurse: Concept analysis. Journal of Clinical Nursing, 24, 318-331. 
Meyer, S.; Van Niekerk, S. E.; Shangase, N. C. \& Naudé M. 2011. The Nursing Unit Manager: A Comprehensive Guide, 3rd ed.; Heinemann: Sandton South Africa, 2011.

Moradi, Y., Mollazadeh, F., Jamshidi, H., Tayefeh, T., Zaker, M. R., \& Karbasi, F. 2017. Outcomes of professional socialization in nursing: A systematic review. Journal of Pharmaceutical Sciences and Research, 9(12), 2468- 2472.

Muthathi, I.S., Thurling, C.H. \& Armstrong, S.J., 2017, 'Through the eyes of the student: Best practices in clinical facilitation', Curationis 40(1), 1787.

Niederriter, J.W., Eyth, D. \& Thoman, J. 2017. Nursing Students' Perceptions on Characteristics of an Effective Clinical Instructor. SAGE Open Nursing. 3: 1-8.

Nsiah, C., Siakwa, M. \& Ninnoni, J.P. 2019. Registered Nurses' description of patient advocacy in the clinical setting, Nursing Open 6(9).

Council, S.A.N.C and VERPLEGING, S.A.R.O., 2005. Nursing Act, 2005 (Act No. 33 of 2005). Government Gazette. Pretoria: Government Printers.

Paliadelis, $P$ and Wood, $P$ 2016. Learning from clinical placement experience: analysing nursing students' final reflections in a digital storytelling activity, Nurse Education in Practice, 20, 39-44.

Polit, D. F., \& Beck, C. T. (2014). Essentials of nursing research: Appraising evidence for nursing practice. Philadelphia, PA: Wolters Kluwer/Lippincott/Williams \& Wilkins Health. 
Pront, L. and McNeill, L., 2019. Nursing students' perceptions of a clinical learning assessment activity: 'Linking the puzzle pieces of theory to practice'. Nurse education in practice, 36, pp.85-90.

Quinn, B.L. and McAuliffe, D., 2019. “There was only one nurse for everyone”: Student reflections of a school nursing clinical experience. Journal of pediatric nursing, 48, pp.72-76.

Setati, C., \& Nkosi, Z. 2017. The perceptions of professional nurses on student mentorship in clinical areas: A study in Polokwane municipality hospitals, Limpopo province. Health SA Gesondheid, 22, 130-137.

Shaw, K. \& Timmons, S. 2010. Exploring how nursing uniforms influence self-image and professional identity. Nursing times. 106 (10),21-3.

Tang, F.W.K. \& Chan, A.W.K. 2019. Learning experience of nursing students in a clinical partnership model: An exploratory qualitative analysis. Nurse Educ Today. 75:6-12.

White, S, Stainer, L, Cooper, K and Waight, S. 2018. The personal tutor as a role model for students: humanising nursing care, British Journal of Nursing, 27,1.

Wills, N.L., Wilson, B., Woodcock, E.B. \& Gillum, D. 2018. Appearance of Nurses and Perceived Professionalism. International Journal of Studies in Nursing 3(3):30. 